\title{
Treatment response and bleeding events associated with anticoagulant therapy of portal vein thrombosis in cirrhotic patients: Systematic review and meta-analysis
}

\author{
Babu P. Mohana, Veeraraghavan Meyyur Aravamudan, Shahab Rasool Khan', Suresh Ponnadad, \\ Ravishankar Asokkumare, Douglas G. Adler ${ }^{2}$
}

University of Arizona, Banner University Medical Center, Tucson, AZ, USA; Woodlands Health Campus, Singapore; Rush University Medical Center, Chicago, IL, USA; Carilion Roanoke Memorial Hospital, Roanoke, Virginia, USA; Singapore General Hospital, Singapore; University of Utah Health, Salt Lake City, UT, USA

\section{Abstract}

Background Well-defined guidelines for the treatment of portal vein thrombosis (PVT) in patients with cirrhosis are lacking, given the paucity of robust data. Among the available treatment options the best choice is unknown.

Methods We conducted a comprehensive search of multiple electronic databases and conference proceedings (through December 2019) to identify studies that reported on the use of anticoagulants in the treatment of PVT in patients with cirrhosis. Our goals were to evaluate the pooled odds ratio $(\mathrm{OR})$ and pooled rate of treatment responders and bleeding events.

Results A total of 17 studies were included: 648 patients were treated with anticoagulation and 96 were controls. Pooled OR for treatment responders was 5.1 (95\% confidence interval [CI] 2.5-10.2, $\mathrm{P}=0.001)$ and pooled $\mathrm{OR}$ for bleeding was $0.4(95 \% \mathrm{CI} 0.1-1.5, \mathrm{P}=0.2)$ for anticoagulation treatment versus control. Pooled rate of treatment responders with anticoagulation was $66.7 \%$ (95\%CI 58.3-74.1) compared to $26 \%$ (95\%CI 14.2-42.7) for the control group. Pooled rate of bleeding seemed comparable (7.8\%, 95\%CI 4.5-13.3, and 15.4\%, 95\%CI 4.3-42.7). On subgroup analysis, pooled rates of treatment responders and bleeding events seemed similar between low molecular weight heparin, vitamin $\mathrm{K}$ antagonists, and direct oral anticoagulants.

Conclusions Our study demonstrated that anticoagulation is effective and safe in the treatment of PVT in patients with cirrhosis. Owing to the comparable outcomes, direct oral anticoagulants may be considered as first-line treatment, depending on patient preferences.

Keywords Portal vein thrombosis, cirrhosis, direct oral anticoagulants, meta-analysis

Ann Gastroenterol 2020; 33 (4): 1-17

${ }^{a}$ Division of Gastroenterology and Hepatology, University of Utah School of Medicine, Salt Lake City, UT, USA; ${ }^{b}$ Department of Medicine, Woodlands Health Campus, Singapore; 'Section of Gastroenterology, Rush University Medical Center, Chicago, Illinois, USA; ${ }^{\mathrm{d}}$ Internal Medicine, Carilion Roanoke Memorial Hospital, Roanoke, Virginia, USA; ${ }^{\mathrm{e}}$ Department of Gastroenterology and Hepatology, Singapore General Hospital, Singapore

Conflict of Interest: None

Correspondence to: Douglas G. Adler MD, FACG, AGAF, FASGE, Professor of Medicine, Director of Therapeutic Endoscopy, Directory, GI fellowship Program, Gastroenterology and Hepatology, University of Utah School of Medicine, Huntsman Cancer Center, 30N 1900E 4R118, Salt Lake City, Utah 84132, USA, e-mail: Douglas.adler@hsc.utah.edu

Received 24 January 2020; accepted 21 April 2020; published online 30 May 2020

DOI: https://doi.org/10.20524/aog.2020.0503

\section{Introduction}

Portal vein thrombosis (PVT) is defined as a clot within the portal vein trunk and/or its intrahepatic branches, the mesenteric vein, the hepatic veins and the splenic veins. PVT can be completely or partially occlusive and can be a lifethreatening event if it extends into the superior mesenteric vein $[1,2]$. Although the impact of PVT on the natural history of patients with cirrhosis is not well established, some evidence suggests that PVT may contribute to a poor prognosis in patients undergoing liver transplantation [3].

The natural course of untreated PVT is not known. Several studies have shown spontaneous resolution and/or no change in $30-75 \%$ of cases, and worsening in most of the remainder [4]. Evidence suggests that a majority of these patients will benefit from some form of anticoagulation. 
Robust data on the optimal management of PVT in patients with cirrhosis are lacking and current guidelines do not propose definitive evidence-based treatment strategies [3]. The best choice of anticoagulation is unknown in cirrhotic patients with PVT.

The classes of anticoagulant therapy for PVT in cirrhosis are vitamin $\mathrm{K}$ antagonists (VKA), low molecular weight heparin (LMWH), and, to a lesser extent, direct oral anticoagulants (DOAC). DOAC in this context have been used in an "off-label" manner and current evidence is limited on its use in the treatment of PVT in patients with cirrhosis. We conducted this meta-analysis to update our knowledge of the use of anticoagulation in PVT patients with cirrhosis, focusing particularly on evidence concerning the use of DOAC.

\section{Materials and methods}

\section{Search strategy}

We conducted a comprehensive search of several databases and conference proceedings, including PubMed, EMBASE, Google-Scholar, LILACS and Web of Science databases (earliest inception to December 2019). We followed the Preferred Reporting Items for Systematic Reviews and MetaAnalyses (PRISMA) and Meta-analysis of Observational Studies in Epidemiology (MOOSE) guidelines [5,6], by using a predefined protocol to identify studies reporting on the treatment of PVT in patients with cirrhosis. PRISMA and MOOSE checklists are provided in Appendices 2 and 3 respectively.

An experienced medical librarian helped with the literature search, using inputs from the study authors. The detailed search strategy is provided in Appendix1. Three authors (BPM, VM, SRK) independently reviewed the title and abstract of studies identified in the primary search and excluded studies that did not address the research question, based on pre-specified exclusion and inclusion criteria. The full text of the remaining articles was reviewed to determine whether it contained relevant information. Any discrepancy in article selection was resolved by consensus and in discussion with a co-author.

The bibliographic section of the selected articles, as well as the systematic and narrative articles on the topic were manually searched for additional relevant articles.

\section{Study selection}

In this meta-analysis, we included studies that evaluated the performance of anticoagulants in the treatment of PVT in patients with cirrhosis. Studies were included irrespectively of the site of thrombus (main portal vein and/or branches, main mesenteric vein and/or branches, main hepatic vein and/or branches, and main splenic vein and/or branches), inpatient/outpatient setting, geography, and abstract/manuscript status, as long as they provided data needed for the analysis. Special attention was focused on data pertaining to patency of the portal vein and its branches, the mesenteric vein, splenic veins, and hepatic veins.

Patients treated with VKA were pre-treated with LMWH for 5-7 days and/or until the international normalized ratio (INR) increased at least to 2.0. The dose of VKA was adjusted to a target INR of 2.0-3.0. LMWH was administered at a treatment dose of $1 \mathrm{mg} / \mathrm{kg}$ body weight subcutaneously. Danaparoid sodium (Orgaran; MSD, Tokyo, Japan) was administered as intravenous drip infusion at a dose of 2500 units/day for a total of 2 weeks.

Response to treatment was assessed by the change in diameter of the thrombus at scheduled follow up. Complete resolution was defined as disappearance of all evidence of thrombosis, determined by transverse computed tomography (CT). Partial resolution was defined as at least a $30 \%$ reduction in the long diameter of the main thrombus and/or 50\% reduction in the cross-sectional area, without evidence of appearance of new thrombi. Patients with partial or complete resolution were considered as responders to treatment.

Clinically significant bleeding was defined based on the location of critical organs-cranium, spine, ocular, retroperitoneal, pericardial, urinary tract, and intramuscular with compartment syndrome-along with a decrease in hemoglobin level $\geq 2 \mathrm{~g} / \mathrm{dL}$ and the need for transfusion of blood products.

Our study's exclusion criteria included: 1) studies with underlying hepatocellular carcinoma and/or metastases; 2) studies with other malignancy-related PVT; 3) studies reporting on arterial thrombosis; 4) studies reporting on patients with underlying thrombogenic hematologic disorders unrelated to cirrhosis; 5) studies on patients with Budd-Chiari syndrome; 6) studies reporting on patients with prior trans-jugular intra-hepatic portosystemic shunt procedure; 7) studies with a sample size $<10$ patients; 8) studies in a pediatric population (age $<18$ years); and 9) studies published in a language other than English.

In case of multiple publications from the same cohort or overlapping cohorts, data from the most recent and/or most appropriate comprehensive report were included. PVT was diagnosed by helical CT and/or Doppler ultrasonography. Angiography and/or magnetic resonance imaging was used as and when needed to confirm a doubtful diagnosis.

\section{Data abstraction and quality assessment}

Data on study-related outcomes in the individual studies were abstracted onto a standardized form by at least 2 authors (VM, SRK), and 2 authors (BPM, SRK) did the quality scoring independently. Data from randomized trials and case-control studies were calculated as number of reported events (n) out of total number of patients $(\mathrm{N})$ from each study. Since the collected data were treated in similar fashion to those from 
single-group cohort studies, we used the Newcastle-Ottawa scale to assess the quality of studies [7]. The details are given in Supplementary Table 1.

\section{Outcomes assessed}

Pooled rate of treatment responders, anticoagulation versus control, and pooled rate of bleeding, anticoagulation versus control. Subgroup analysis was based on the type of anticoagulant (VKA, LMWH or DOAC).

\section{Statistical analysis}

We used meta-analysis techniques to calculate the pooled estimates in each case, following the random-effects model. When the incidence of an outcome was zero in a study, a continuity correction of 0.5 was added to the number of incident cases before statistical analysis [8]. We assessed heterogeneity between study-specific estimates using the Cochran Q statistical test for heterogeneity $[9,10]$ and the $I^{2}$ statistic $[11,12]$. In this test, values of $<30 \%, 30-60 \%, 61-75 \%$ and $>75 \%$ were suggestive of low, moderate, substantial and considerable heterogeneity, respectively [13]. Publication bias was ascertained qualitatively, by visual inspection of a funnel plot, and quantitatively, by the Egger test [14]. When publication bias was present, further statistics using the failsafe $\mathrm{N}$ test and Duval and Tweedie's "Trim and Fill” test was used to ascertain the impact of the bias [15]. Three levels of impact were reported, based on the concordance between the reported results and the actual estimate if there were no bias. The impact was reported as minimal if both versions were estimated to be the same, modest if effect size changed substantially but the final finding would still remain the same, and severe if the basic final conclusion of the analysis was threatened by the bias [16]. We ran meta-regression analysis based on the random-effects Knapp-Hartung method to evaluate effects of variables on the analyzed outcomes. All analyses were performed using Comprehensive Meta-Analysis (CMA) software, version 3 (BioStat, Englewood, NJ).

\section{Results}

\section{Search results and population characteristics}

From an initial total of 1147 studies, 523 records were screened and 71 full-length articles were assessed. 17 studies were included in the final analysis [17-33]. Five studies reported on LMWH [17,22,23,25,32], 8 reported on VKA [19-21,24,26,27,29,33], and 3 reported on DOAC [26,29,31]. Two studies reported anticoagulation in general $[18,30]$, and one study used danaparoid alone [28]. Six studies reported on patients with PVT who were not treated with anticoagulation and were used as the control cohort $[20,21,23,25,30,32]$. The schematic diagram of the study selection is illustrated in Supplementary Fig. 1.

Baseline population characteristics were comparable between the VKA, LMWH, DOAC, and control groups. The mean and/or median age ranged from $41-71$ years, with a predominantly male population (70.6\%). Alcoholic (45.3\%) and viral (40.3\%) causes of cirrhosis were the most common, followed by autoimmune and biliary causes (14.4\%). There were 144 patients with Child-Pugh A, 182 patients with Child-Pugh B, and 121 with Child-Pugh $\mathrm{C}$ cirrhosis. The majority of the studies had patients screened for esophageal varices before the initiation of anticoagulation. Patients with grade II or III esophageal varices were banded and anticoagulation initiation was delayed until 15 days after the last banding session. Unfortunately, studies did not report uniformly on the details of banding prior to anticoagulation initiation. The basic study and population characteristics are described in Supplementary Table 1 .

\section{Characteristics and quality of included studies}

Two studies were prospective and the rest were retrospective in nature $[23,32]$. Two were multicenter studies $[22,26]$ and the rest were single-centered. None were population-based. The details of the quality assessment are summarized in Supplementary Table 2. Overall, 8 studies were considered to be of high quality $[20-24,26,29,32]$ and the rest were of medium quality. There were no low quality studies.

\section{Outcomes}

A total of 744 patients were included in the analysis from the 17 studies [17-33]. A pooled odds ratio (OR) was calculated from 6 studies that compared anticoagulation to controls. The pooled OR for treatment responders was 5.1 (95\% confidence interval $[\mathrm{CI}] 2.5-10.2, \mathrm{P}=0.001, I^{2}=13 \%$ ) (Fig. 1), and the pooled OR for bleeding was 0.4 (95\%CI $0.1-1.5, \mathrm{P}=0.2$, $I^{2}=0 \%$ ) (Fig. 2).

The pooled rate of treatment responders was $66.7 \%$ (95\%CI 58.3-74.1, $I^{2}=72.7 \%$ ) and the pooled rate of treatment responders in the control group (no treatment), was $26 \%$ (95\%CI 14.2-42.7, $I^{2}=36.7 \%$ ) (Supplementary Fig. 2). The pooled rate of bleeding with anticoagulation was $7.8 \%$ (95\%CI 4.5-13.3, $I^{2}=66.2 \%$ ), and the pooled rate of bleeding in the control group was $15.4 \%$ (95\%CI $\left.4.3-42.7, I^{2}=0 \%\right)$ (Supplementary Fig. 3).

\section{Subgroup analysis}

Subgroup analysis was based on the anticoagulation type, i.e., LMWH, VKA, and DOAC: 155 patients were treated with LMWH, 315 with VKA, and 70 with DOAC. The pooled rate of treatment response was $60.7 \%$ (95\%CI 41.5-77.2) for LMWH, 66\% (95\%CI 51.1-78.3) for VKA, and 76.7\% (95\%CI 45.3-92.9) 


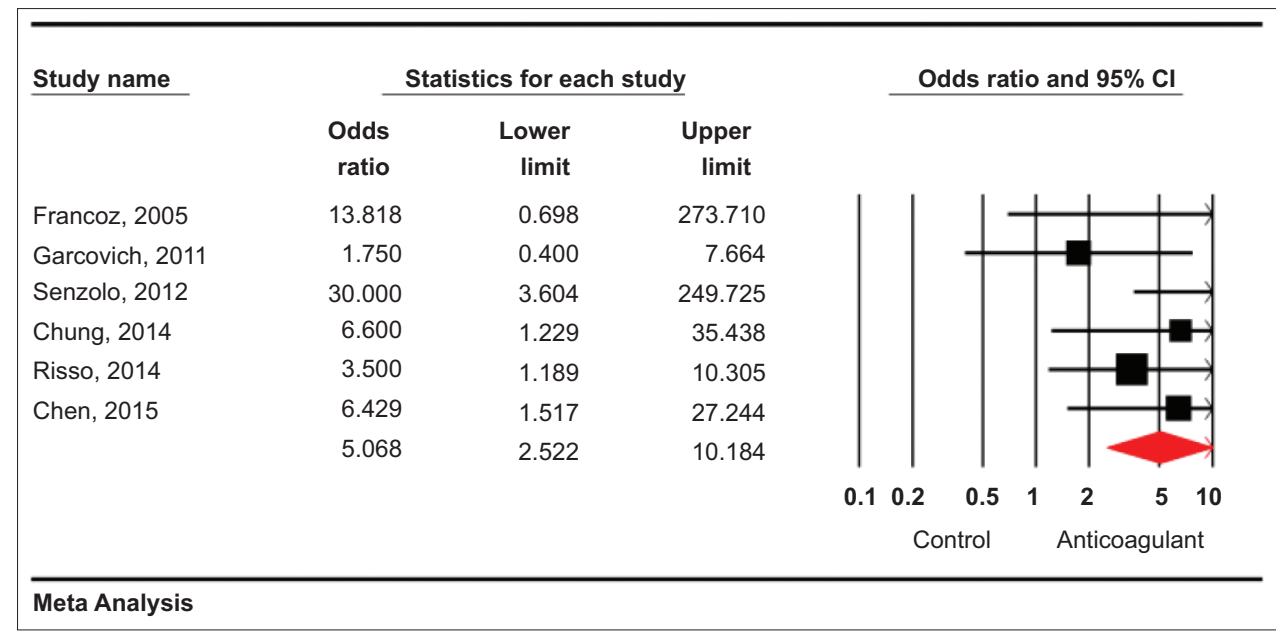

Figure 1 Forest plot. Treatment responders: Pooled odds ratio (OR), anticoagulation vs. control

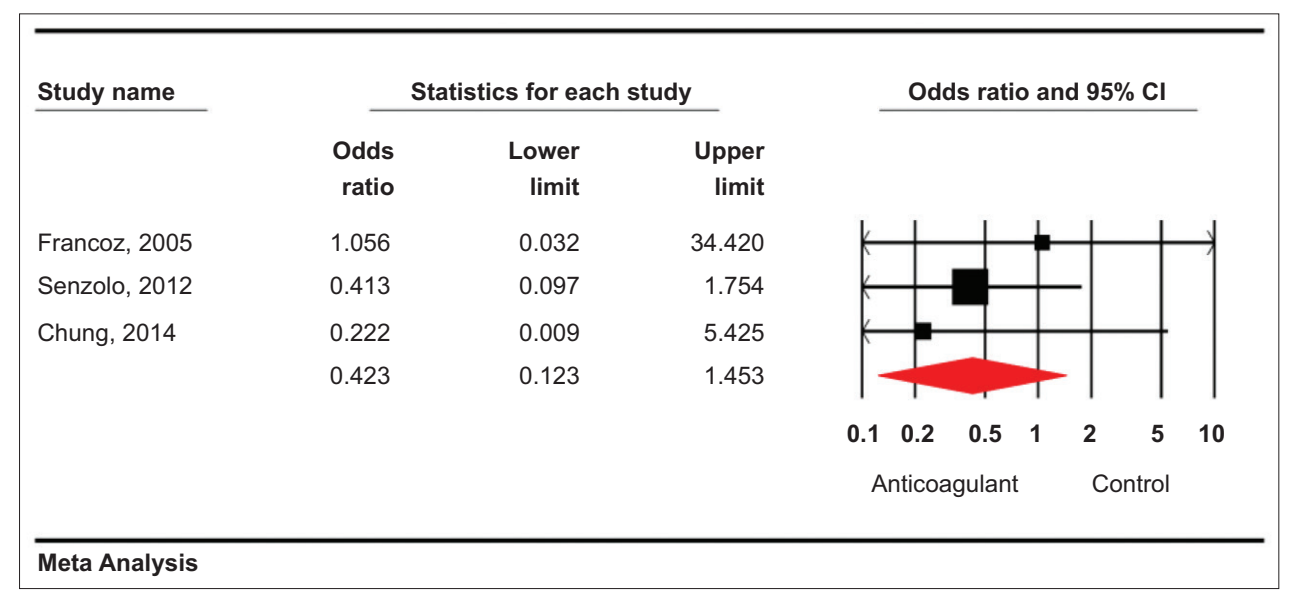

Figure 2 Forest plot. Bleeding: Pooled odds ratio (OR), anticoagulation vs. control

for DOAC (Supplementary Fig. 4). The pooled rate of bleeding was 7.2\% (95\%CI 2.1-21.6) for LMWH, 9.3\% (95\%CI 3.9-20.6) for VKA, and 7.9\% (95\%CI 1.7-29.9) for DOAC (Supplementary Fig. 5). These rates appeared comparable (Table 1).

\section{Meta-regression analysis based on Child-Pugh classification}

Child-Pugh classifications A, B and C did not significantly affect the pooled rates of treatment success or the pooled rates of bleeding. The calculated 2-sided P-value of the intercept was 0.39: Child A was 0.15 , Child B was 0.11 , and Child C was 0.15 .

\section{Validation of meta-analysis results}

\section{Sensitivity analysis}

To assess whether any one study had a dominant effect on the meta-analysis, we excluded one study at a time and analyzed its effect on the main summary estimate. On this analysis, no single study significantly affected the outcome or the heterogeneity.

\section{Heterogeneity}

We assessed the dispersion of the calculated rates using the $I^{2}$ percentage values. The pooled $\mathrm{OR}$ with treatment responders and/or bleeding demonstrated minimal to no heterogeneity. The pooled rate of treatment responders with anticoagulation demonstrated considerable to moderate heterogeneity. Meta-regression analysis and subgroup analysis did not demonstrate a statistical explanation for the observed heterogeneity.

\section{Publication bias}

Based on visual inspection of the funnel plot, as well as quantitative measurement that used the Egger regression test, there was evidence of publication bias. Further statistics 
Table 1 Summary of pooled results

\begin{tabular}{|c|c|c|c|c|c|c|c|c|}
\hline \multirow[t]{2}{*}{ Group } & \multicolumn{4}{|c|}{ Treatment responders } & \multicolumn{4}{|c|}{ Bleeding } \\
\hline & Pooled rate & $95 \% \mathrm{CI}$ & $I^{2} \%$ & P-value & Pooled rate & $95 \% \mathrm{CI}$ & $I^{2} \%$ & P-value \\
\hline All anticoagulants vs. controls & OR 5.1 & $2.5-10.2$ & 13 & 0.001 & OR 0.4 & $0.1-1.5$ & 0 & 0.2 \\
\hline All anticoagulants & $66.7 \%$ & $58.3-74.1$ & 72.7 & 0.001 & $7.8 \%$ & $4.5-13.3$ & 66.2 & 0.33 \\
\hline Control & $26 \%$ & $14.2-42.7$ & 36.7 & & $15.4 \%$ & $4.3-42.7$ & 0 & \\
\hline VKAs & $66 \%$ & $51.1-78.3$ & 80.7 & & $9.3 \%$ & $3.9-20.6$ & 78.2 & \\
\hline LMWH & $60.7 \%$ & $41.5-77.2$ & 57 & & $7.2 \%$ & $2.1-21.6$ & 0 & \\
\hline DOAC & $76.7 \%$ & $45.3-92.9$ & 88.5 & & $7.9 \%$ & $1.7-29.9$ & 30.3 & \\
\hline LMWH vs. VKAs & & & & 0.63 & & & & 0.33 \\
\hline DOACs vs. LMWH & & & & 0.35 & & & & 0.74 \\
\hline DOAC vs. VKA & & & & 0.5 & & & & 0.9 \\
\hline
\end{tabular}

CI, confidence interval; OR, odds ratio; VKA, Vitamin-K antagonists; LMWH, low molecular weight heparin; DOAC, direct oral anticoagulation

using the fail-safe $\mathrm{N}$ test and Duval and Tweedie's “Trim and Fill" test revealed that the impact of the possible publication bias appeared to be minimal and would not change the calculated estimate or the conclusion of this meta-analysis (Supplementary Fig. 6).

\section{Discussion}

This study demonstrated that the pooled OR of treatment response was statistically significant (OR 5.1, 95\% CI 2.5-10.2; $\mathrm{P}=0.001$ ) with respect to anticoagulation therapy of PVT, as compared to controls, in patients with cirrhosis. The pooled OR of bleeding events was 0.4 (95\%CI $0.1-1.5)$ and was not significant $(P=0.2)$. To the best of our knowledge, this study is the largest and most current review of anticoagulation therapy of PVT in patients with cirrhosis.

Our study results add important data to the current literature, since this is the first study to analyze the pooled rates of DOAC in the treatment of PVT, and the first to analyze the effect of Child-Pugh classification on the pooled rates by metaregression methods. However, it is important to note that metaregression analysis is a weak statistical tool in the assessment of a variable's predictive effects on the pooled outcomes, and the result is not in accordance with current clinical experience. Anticoagulation is completely different in a well-compensated cirrhotic patient compared to a decompensated patient. Studies included in this analysis did not specify the treatment in relation to the Child score.

The pooled rate of treatment response with anticoagulation was $66.7 \%$ and the pooled rate in the control group was $26 \%$. Based on the subgroup analysis, the pooled rate of treatment response was $60.7 \%$ for $\mathrm{LMWH}, 66 \%$ for VKA, and $76.7 \%$ for DOAC. Although our results do not establish causality, they clearly indicate that anticoagulation therapy of PVT in patients with cirrhosis is more beneficial than no treatment. The treatment duration in the studies included ranged from 2 weeks in the case of danaparoid followed by VKA to 17 months in the case of LMWH. In the case of DOAC the treatment was given for 6 months.

Patients with cirrhosis are considered to be more prone to develop PVT compared to patients without cirrhosis, with a reported incidence in the range of $9-11 \%$, far higher than that of the general population [34,35]. Patients with advanced liver cirrhosis and PVT tend to have lower activated partial thromboplastin time and INR. Apart from deranged coagulation parameters, a decreased velocity of portal vein flow, with or without flow reversal, seems to be an important factor predisposing to thrombus formation [36,37]. Based on our results, anticoagulation therapy seems warranted in patients with cirrhosis; however, this cannot be generalized at present, as there are many different phenotypes of cirrhotics and the current major societies differ in their opinion.

The pooled rate of bleeding with anticoagulation was $7.8 \%$ : 7.2\% with LMWH, 9.3\% with VKA, and 7.9\% with DOAC. Our analysis demonstrated comparable rates of life-threatening bleeding events with LMWH, VKA, and DOAC. The majority of reported bleeding events, especially variceal, were located in the gastrointestinal tract. Patients with high-grade varices were typically banded before anticoagulation therapy and treatment was typically delayed by 15 days. Variceal bleed with any anticoagulation, especially a DOAC, can be potentially lifethreatening. The pooled rate of bleeding in the control group was $15.4 \%$.

Although, the United States Food and Drug Administration has approved novel antidotes for DOAC, they are not widely available for use, especially in resourcelimited settings, because of cost issues. LMWH and/or VKA may be a safer option in patients with severe varices, given the readily available antidotes. In the studies analyzed, no bleeding-related deaths were reported. Based on our meta- 
regression analysis, Child-Pugh classification for the severity of cirrhosis did not seem to influence the measured outcomes. Currently, DOAC are not recommended for use in ChildPugh C cirrhosis.

Overall, the strengths of this review are the systematic literature search with well-defined inclusion criteria, the careful exclusion of redundant studies, the inclusion of good quality studies with detailed extraction of data, the rigorous evaluation of study quality, and the statistics to establish or refute the validity of the results of our meta-analysis. Analysis of DOAC and meta-regression covariate analysis based on the Child-Pugh classification are new additions to the current literature.

There were limitations to this study, most of which are inherent to any meta-analysis. Our analysis included studies retrospective in nature, contributing to selection bias. Although the treatment response was high, we were not able to specify the magnitude of the treatment in relation to the anatomical location of the response, and there was no information on portal cavernoma. Heterogeneity was noted in the analysis of treatment responders, especially in the treatment with VKA. Variability in the time to achieve a target INR with VKA is a plausible explanation, along with the variability in treatment dosage, duration of heparin bridging and differences in anticoagulation medication. We were not able to analyze the treatment outcomes based on the model for end-stage liver disease score, because of the paucity of data. We were not able to evaluate the role of $\beta$-blockers on primary prevention with PVT and plan for anticoagulation.

Our results are comparable with previously conducted meta-analyses $[38,39]$, which reported a recanalization rate of $66-71 \%$ with anticoagulation treatment for PVT in patients with cirrhosis with no excess of major or minor bleedings. In the study sample of Scheiner et al [31], 70\% of the patients had non-cirrhotic PVT. Nagaoki et al [29] used a combination of 3 drugs (danaparoid, ATIII infusion followed by VKA). Hanafy et al [26] compared VKA to DOAC in a cohort of patients that consisted entirely of acute PVT from splenectomy in well-compensated HCV cirrhosis. However, based on our sensitivity analysis, we demonstrated that including or removing one study at a time did not affect the pooled outcomes, so this study is still the best available evidence in the literature thus far. Well-conducted randomized studies are warranted to better predict the usefulness of LMWH, VKA, and DOAC in such patients.

In conclusion, our meta-analysis demonstrated that anticoagulation therapy of PVT should be considered in patients with cirrhosis. The risk of major life-threatening bleeding does not seem to be increased in cirrhotic patients with PVT treated with anticoagulants, compared to patients with no treatment. LMWH, VKA, and DOAC are comparable in the resolution of PVT, with a similar risk of life-threatening bleeding events. Therefore, DOACs may be used for the treatment of PVT in patients with cirrhosis, based on patient preferences and characteristics.

\section{Summary Box}

\section{What is already known:}

- Portal vein thrombosis (PVT) is commonly encountered in patients with cirrhosis and can be life-threatening

- According to the Baveno VI consensus, treatment should be considered in potential livertransplantation candidates; however, no consensus exists for non-transplant candidates

- The consensus is based on weak data and the main concern is the risk of inducing or aggravating a life-threatening bleeding episode

- Additionally, data on the use of direct oral anticoagulants (DOACs) in PVT are limited

\section{What the new findings are:}

- In this meta-analysis of 17 studies, the pooled odds ratio (OR) of treatment responders with any form of anticoagulation therapy for PVT in cirrhotic patients was statistically significant (OR 5.1, 95\% confidence interval [CI] 2.5-10.2; $\mathrm{P}=0.001)$, when compared to no anticoagulation

- The pooled proportion of treatment responders was $60.7 \%$ for low molecular weight heparin (LMWH), 66\% for vitamin $\mathrm{K}$ antagonists (VKA), and $76.7 \%$ for DOACs

- The pooled odds ratio (OR 0.4, 95\%CI 0.1-1.5; $\mathrm{P}=0.2$ ) showed that the bleeding risk in cirrhotic patients receiving any form of anticoagulation therapy for PVT was comparable to that in patients who received no anticoagulation

- The pooled bleeding risk seemed comparable for LMWH, VKAs and DOACs $(7.2 \%, 9.3 \%$ and $7.9 \%$, respectively)

\section{References}

1. Yerdel MA, Gunson B, Mirza D, et al. Portal vein thrombosis in adults undergoing liver transplantation: risk factors, screening, management, and outcome. Transplantation 2000;69:1873-1881.

2. Sarin SK, Philips CA, Kamath PS, et al. Toward a comprehensive new classification of portal vein thrombosis in patients with cirrhosis. Gastroenterology 2016;151:574-577.

3. Basili S, Pastori D, Raparelli V, Violi F. Anticoagulant therapy in patients with liver cirrhosis and portal vein thrombosis: insights for the clinician. Therap Adv Gastroenterol 2018;11:1756284818793561.

4. Ageno W, Riva N, Schulman S, et al. Long-term clinical outcomes of splanchnic vein thrombosis: results of an international registry. JAMA Intern Med 2015;175:1474-1480.

5. Moher D, Liberati A, Tetzlaff J, Altman DG; PRISMA Group. Preferred reporting items for systematic reviews and meta-analyses: the PRISMA statement. Ann Intern Med 2009;151:264-269, W64. 
6. Stroup DF, Berlin JA, Morton SC, et al. Meta-analysis of observational studies in epidemiology: a proposal for reporting. Meta-analysis Of Observational Studies in Epidemiology (MOOSE) group. JAMA 2000;283:2008-2012.

7. Stang A. Critical evaluation of the Newcastle-Ottawa scale for the assessment of the quality of nonrandomized studies in metaanalyses. Eur J Epidemiol 2010;25:603-605.

8. Sutton AJ, Abrams KR, Jones DR, et al. Methods for meta-analysis in medical research. New York: John Wiley and Sons Ltd, 2000.

9. Higgins JPT, Thompson SG, Spiegelhalter DJ. A re-evaluation of random-effects meta-analysis. J R Stat Soc Series B Stat Methodol 2009;172:137-159.

10. Riley RD, Higgins JP, Deeks JJ. Interpretation of random effects meta-analyses. BMJ 2011;342:d549.

11. Kanwal F, White D. "Systematic reviews and meta-analyses" in clinical gastroenterology and hepatology. Clin Gastroenterol Hepatol 2012;10:1184-1186.

12. Higgins JP, Thompson SG, Deeks JJ, Altman DG. Measuring inconsistency in meta-analyses. BMJ 2003;327:557-560.

13. Guyatt GH, Oxman AD, Kunz R, et al. GRADE guidelines: 7. Rating the quality of evidence and inconsistency. J Clin Epidemiol 2011;64:1294-1302.

14. Easterbrook PJ, Berlin JA, Gopalan R, Matthews DR. Publication bias in clinical research. Lancet 1991;337:867-872.

15. Duval S, Tweedie R. Trim and fill: A simple funnel-plot-based method of testing and adjusting for publication bias in metaanalysis. Biometrics 2000;56:455-463.

16. Rothstein HR, Sutton AJ, Borenstein M. Publication bias in metaanalysis: Prevention, assessment and adjustments. New York: John Wiley and Sons Ltd, 2005.

17. Amitrano L, Guardascione MA, Menchise A, et al. Safety and efficacy of anticoagulation therapy with low molecular weight heparin for portal vein thrombosis in patients with liver cirrhosis. J Clin Gastroenterol 2010;44:448-451.

18. Artaza T, Lopes M, Romero M, et al. Efficacy and safety of anticoagulation in non-malignant portal vein thrombosis in patients with liver cirrhosis. Gastroenterol Hepatol 2018; 41:611-617.

19. Bento L, Huerta AR, Pascual C, et al. Antithrombotic therapy in non-neoplastic chronic portal venous thrombosis in cirrhosis: recanalization and liver function evaluation: Am Soc Hematology 2011, Abstract 3358

20. Chen H, Liu L, Qi X, et al. Efficacy and safety of anticoagulation in more advanced portal vein thrombosis in patients with liver cirrhosis. Eur J Gastroenterol Hepatol 2016;28:82-89.

21. Chung JW, Kim GH, Lee JH, et al. Safety, efficacy, and response predictors of anticoagulation for the treatment of nonmalignant portal-vein thrombosis in patients with cirrhosis: a propensity score matching analysis. Clin Mol Hepatol 2014;20:384-391.

22. Delgado MG, Seijo S, Yepes I, et al. Efficacy and safety of anticoagulation on patients with cirrhosis and portal vein thrombosis. Clin Gastroenterol Hepatol 2012;10:776-783.

23. Francoz C, Belghiti J, Vilgrain V, et al. Splanchnic vein thrombosis in candidates for liver transplantation: usefulness of screening and anticoagulation. Gut 2005;54:691-697.
24. Fujiyama S, Saitoh S, Kawamura Y, et al. Portal vein thrombosis in liver cirrhosis: incidence, management, and outcome. BMC Gastroenterol 2017;17:112.

25. Garcovich M, Zocco MA, Ainora ME, et al. Clinical outcome of portal vein thrombosis (PVT) in cirrhotic patients: observe or treat? In Hepatology. Malden: Wiley-Blackwell, 2011.

26. Hanafy AS, Abd-Elsalam S, Dawoud MM. Randomized controlled trial of rivaroxaban versus warfarin in the management of acute non-neoplastic portal vein thrombosis. Vascul Pharmacol 2019;113:86-91.

27. La Mura V, Braham S, Tosetti G, et al. Harmful and beneficial effects of anticoagulants in patients with cirrhosis and portal vein thrombosis. Clin Gastroenterol Hepatol 2018;16:1146-1152.

28. Naeshiro N, Aikata H, Hyogo H, et al. Efficacy and safety of the anticoagulant drug, danaparoid sodium, in the treatment of portal vein thrombosis in patients with liver cirrhosis. Hepatol Res 2015;45:656-662.

29. Nagaoki Y, Aikata H, Daijyo K, et al. Efficacy and safety of edoxaban for treatment of portal vein thrombosis following danaparoid sodium in patients with liver cirrhosis. Hepatol Res 2018;48:51-58.

30. Risso A, Stradella D, Martini S, et al. Liver transplantation in cirrhotic patients with portal vein thrombosis: a single centre experience. Dig Liver Dis 2014;46:e40.

31. Scheiner B, Stammet PR, Pokorny S, et al. Anticoagulation in nonmalignant portal vein thrombosis is safe and improves hepatic function. Wien Klin Wochenschr 2018;130:446-455.

32. Senzolo M, M Sartori T, Rossetto V, et al. Prospective evaluation of anticoagulation and transjugular intrahepatic portosystemic shunt for the management of portal vein thrombosis in cirrhosis. Liver Int 2012;32:919-927.

33. Werner KT, Sando S, Carey EJ, et al. Portal vein thrombosis in patients with end stage liver disease awaiting liver transplantation: outcome of anticoagulation. Dig Dis Sci 2013;58:1776-1780.

34. Stine JG, Shah PM, Cornella SL, et al. Portal vein thrombosis, mortality and hepatic decompensation in patients with cirrhosis: A meta-analysis. World J Hepatol 2015;7:2774-2780.

35. Nery F, Chevret S, Condat B, et al; Groupe d'Etude et de Traitement du Carcinome Hépatocellulaire. Causes and consequences of portal vein thrombosis in 1,243 patients with cirrhosis: results of a longitudinal study. Hepatology 2015;61:660-667.

36. Weber A, Krebs S, Lenhardt C, Wagenpfeil S, Schmid RM, SchulteFrohlinde E. Correlation of routinely used coagulation parameters and presence of portal vein thrombosis in patients with liver cirrhosis. Hepatol Res 2009;39:882-887.

37. Wanless IR, Wong F, Blendis LM, Greig P, Heathcote EJ, Levy G. Hepatic and portal vein thrombosis in cirrhosis: possible role in development of parenchymal extinction and portal hypertension. Hepatology 1995;21:1238-1247.

38. Loffredo L, Pastori D, Farcomeni A, Violi F. Effects of anticoagulants in patients with cirrhosis and portal vein thrombosis: a systematic review and meta-analysis. Gastroenterology 2017;153:480-487.

39. Qi X, De Stefano V, Li H, Dai J, Guo X, Fan D. Anticoagulation for the treatment of portal vein thrombosis in liver cirrhosis: a systematic review and meta-analysis of observational studies. Eur J Intern Med 2015;26:23-29. 
Supplementary materials

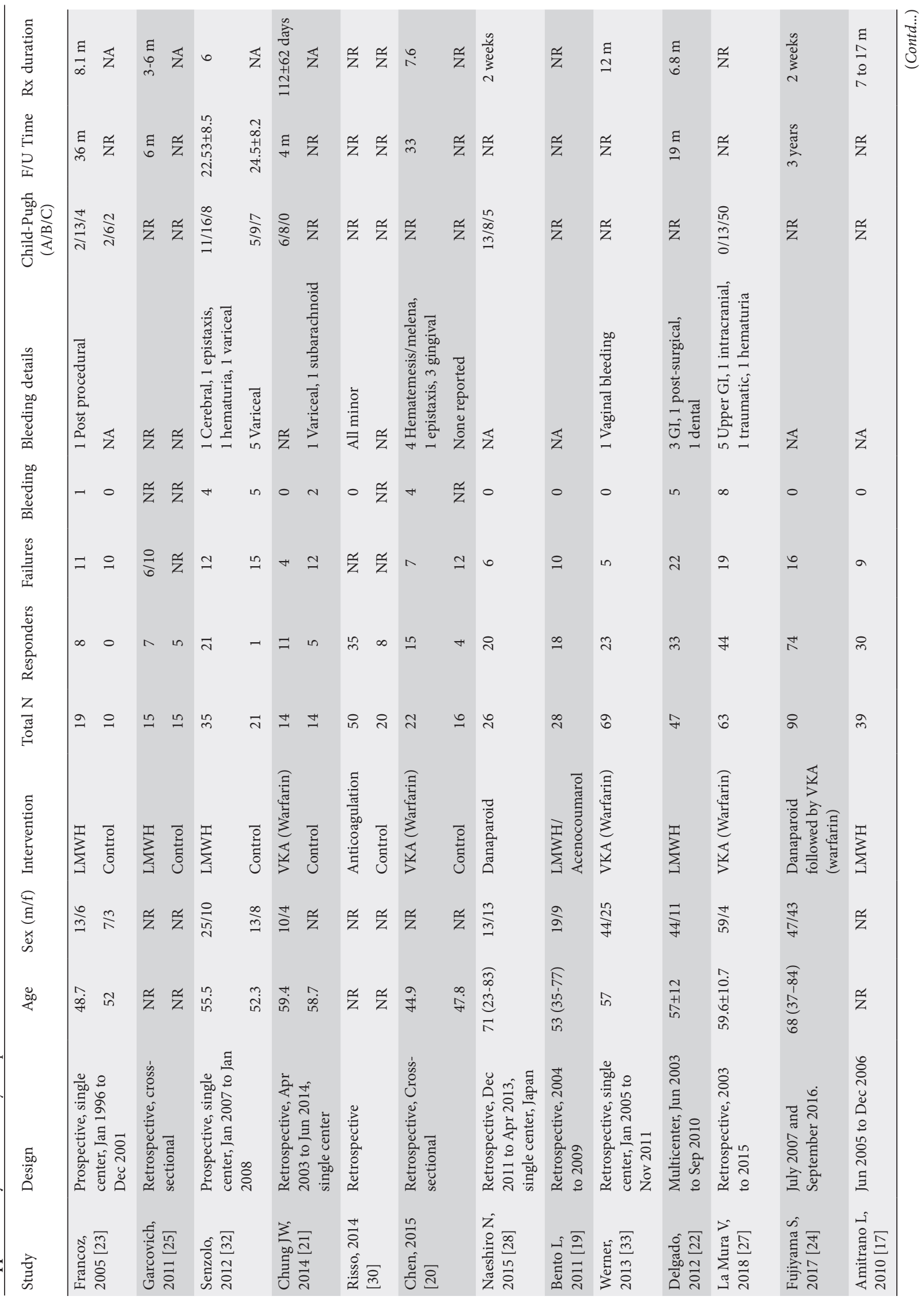



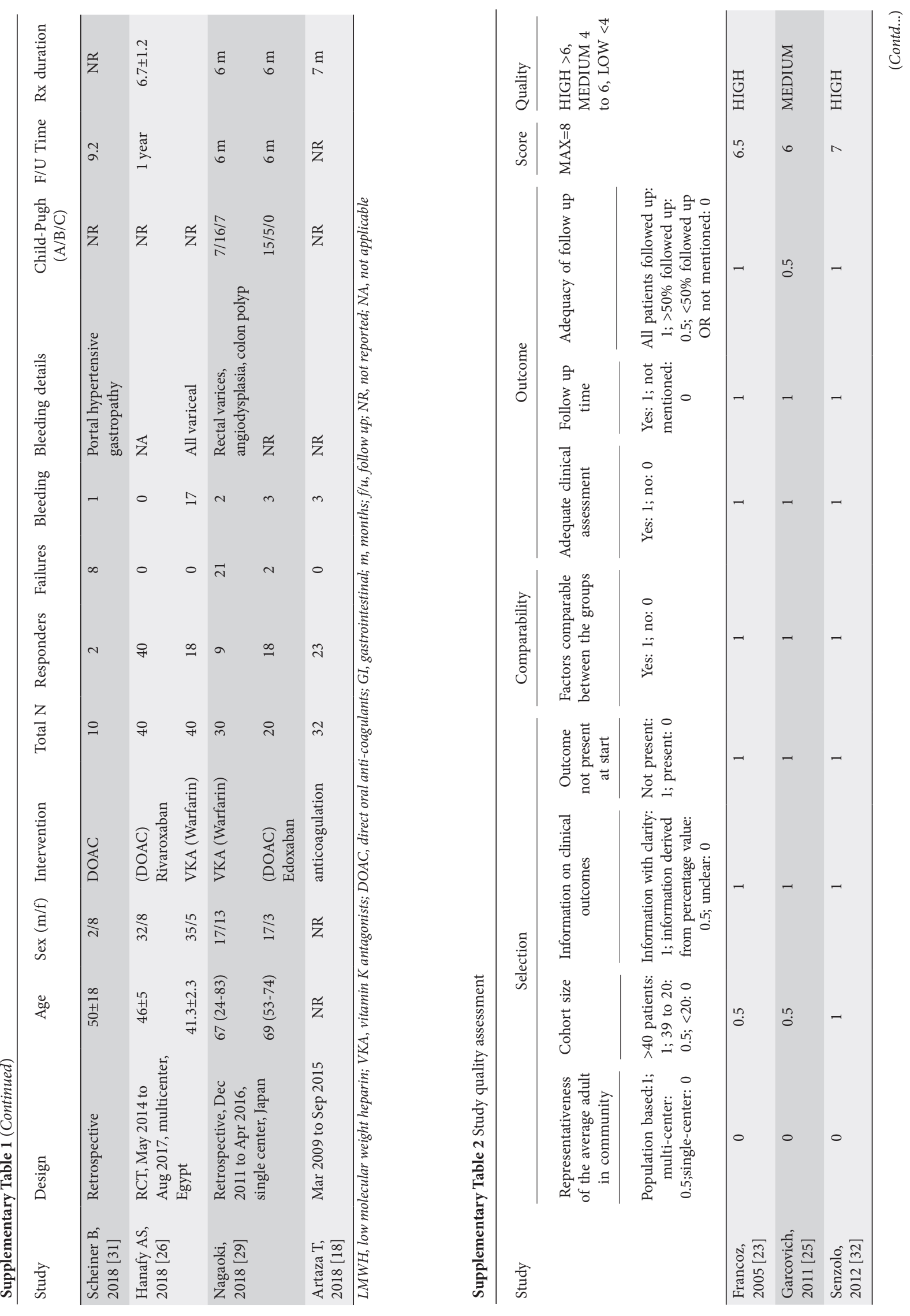


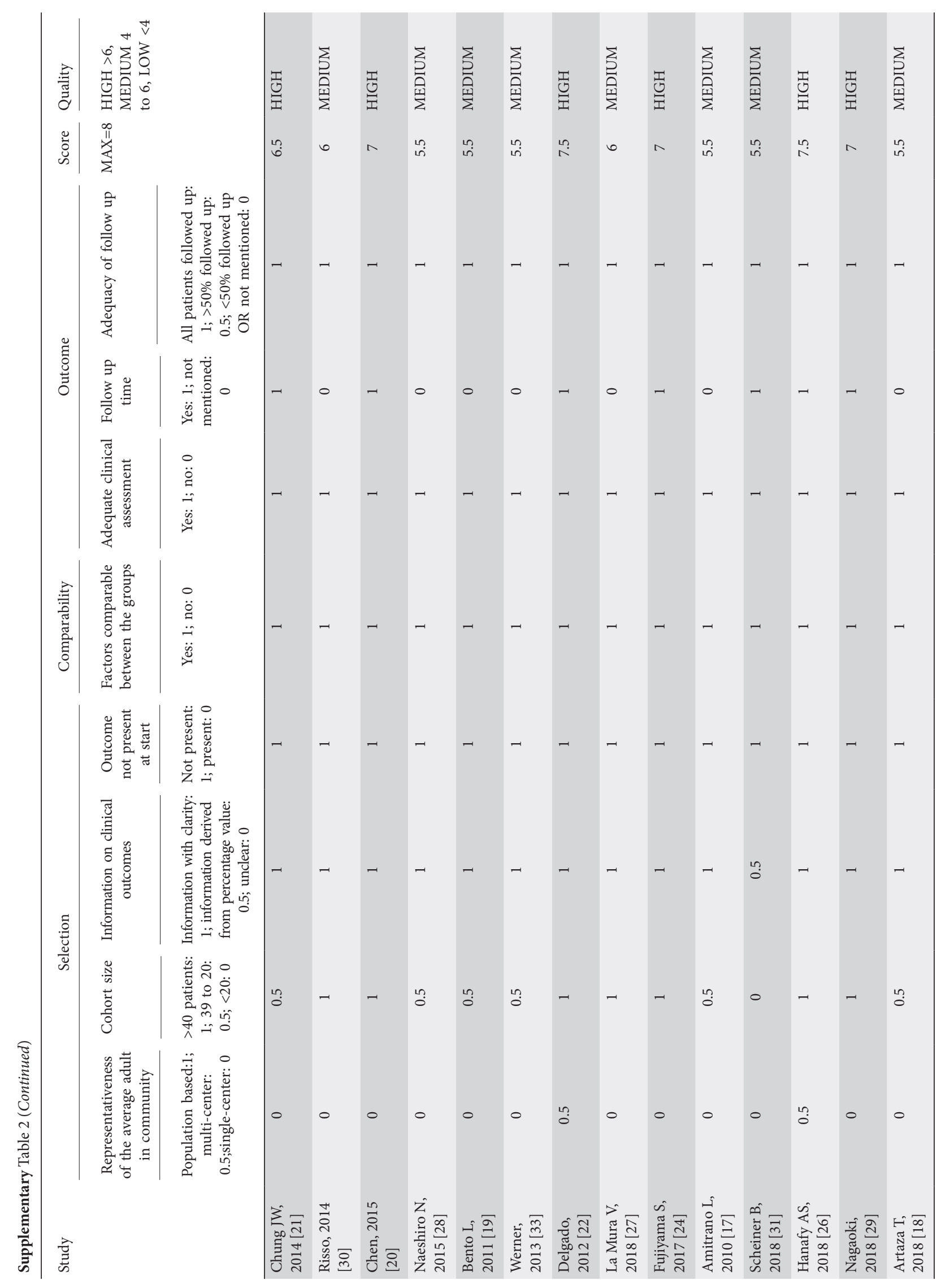




\section{Supplementary Figures}

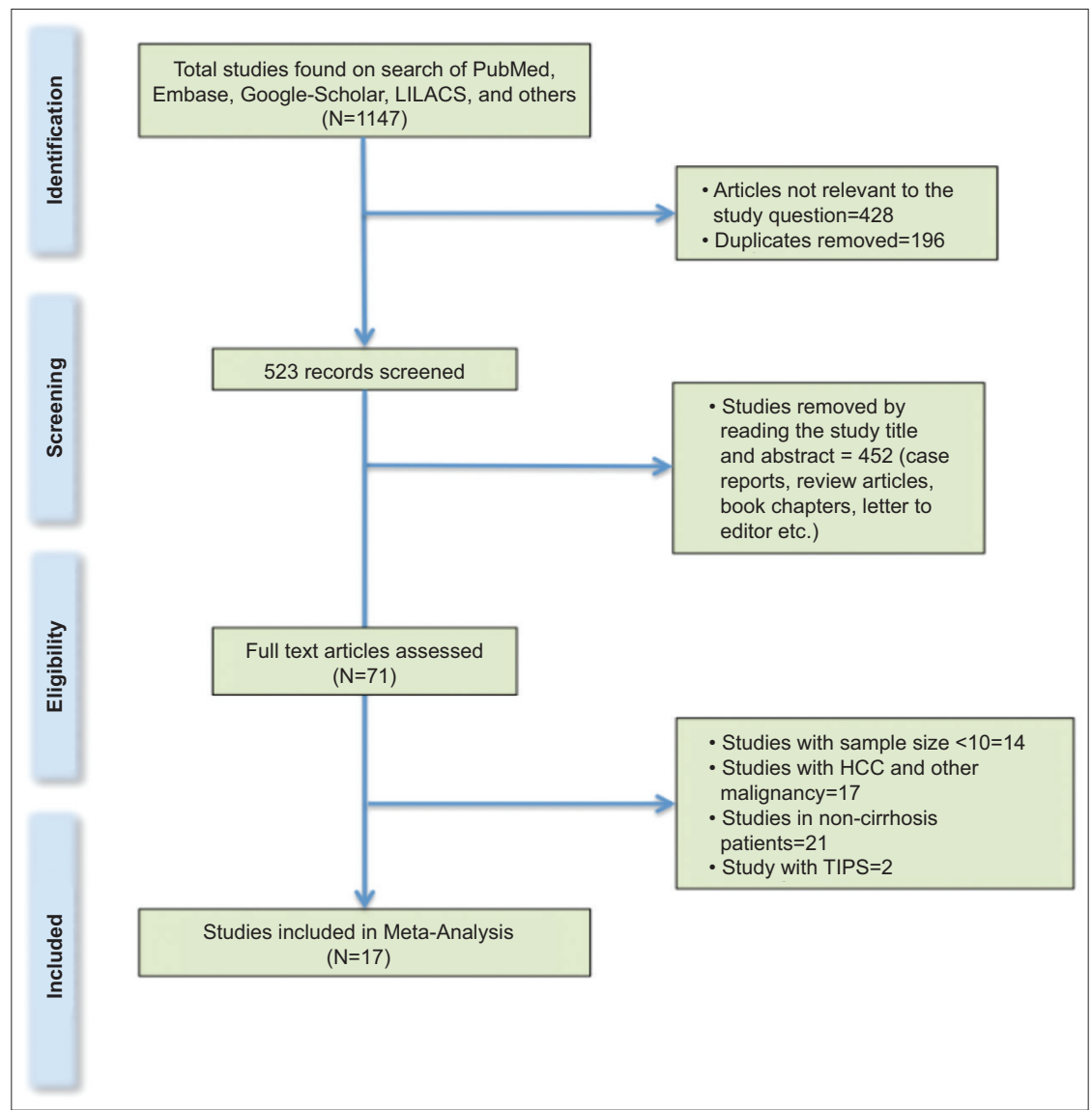

Supplementary Figure 1 Flow diagram of study selection

$P V T$, portal vein thrombosis; HCC, hepato-cellular carcinoma; TIPS, trans-jagular intra-hepatic porto-systemic shunt

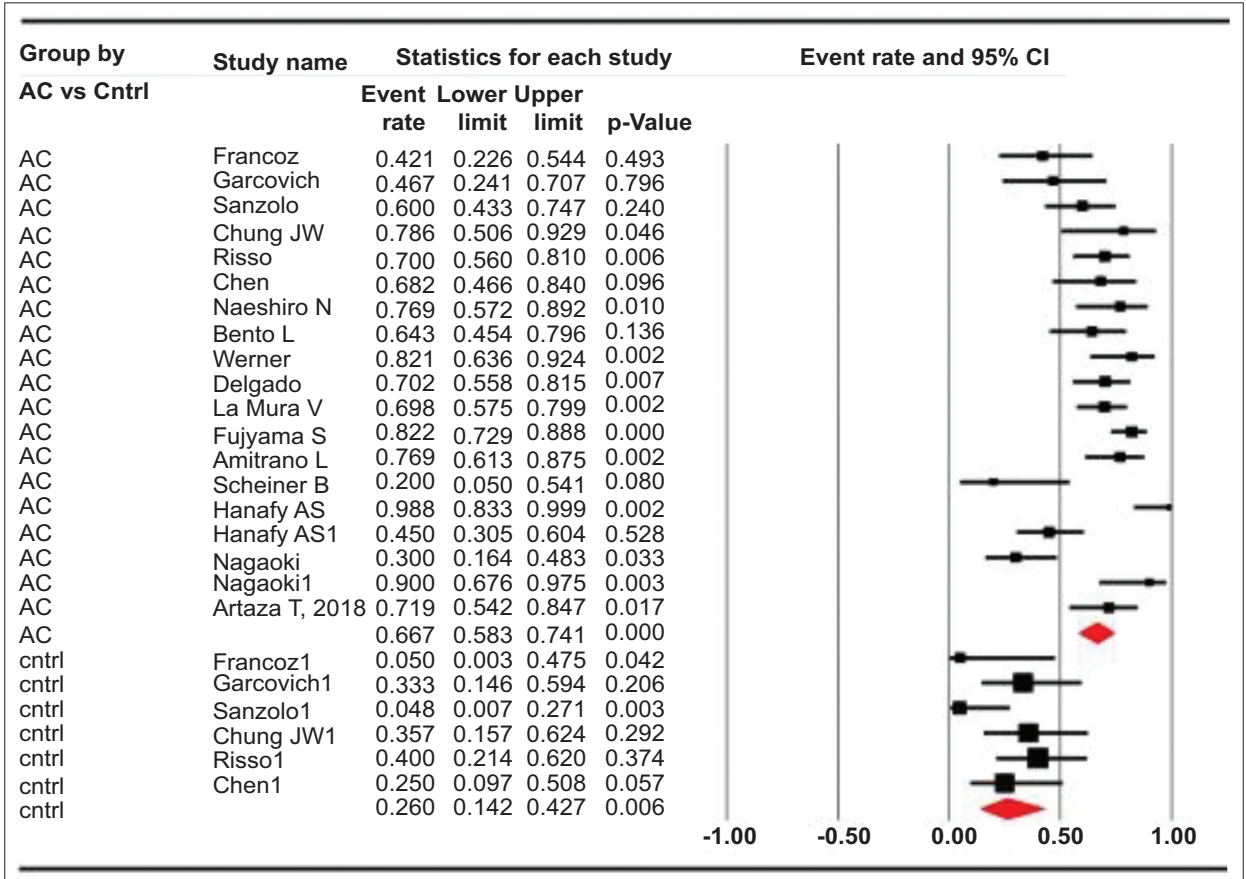

Supplementary Figure 2 Forest plot. Pooled rates, treatment responders: anticoagulation (AC) vs. control (cntrl) 


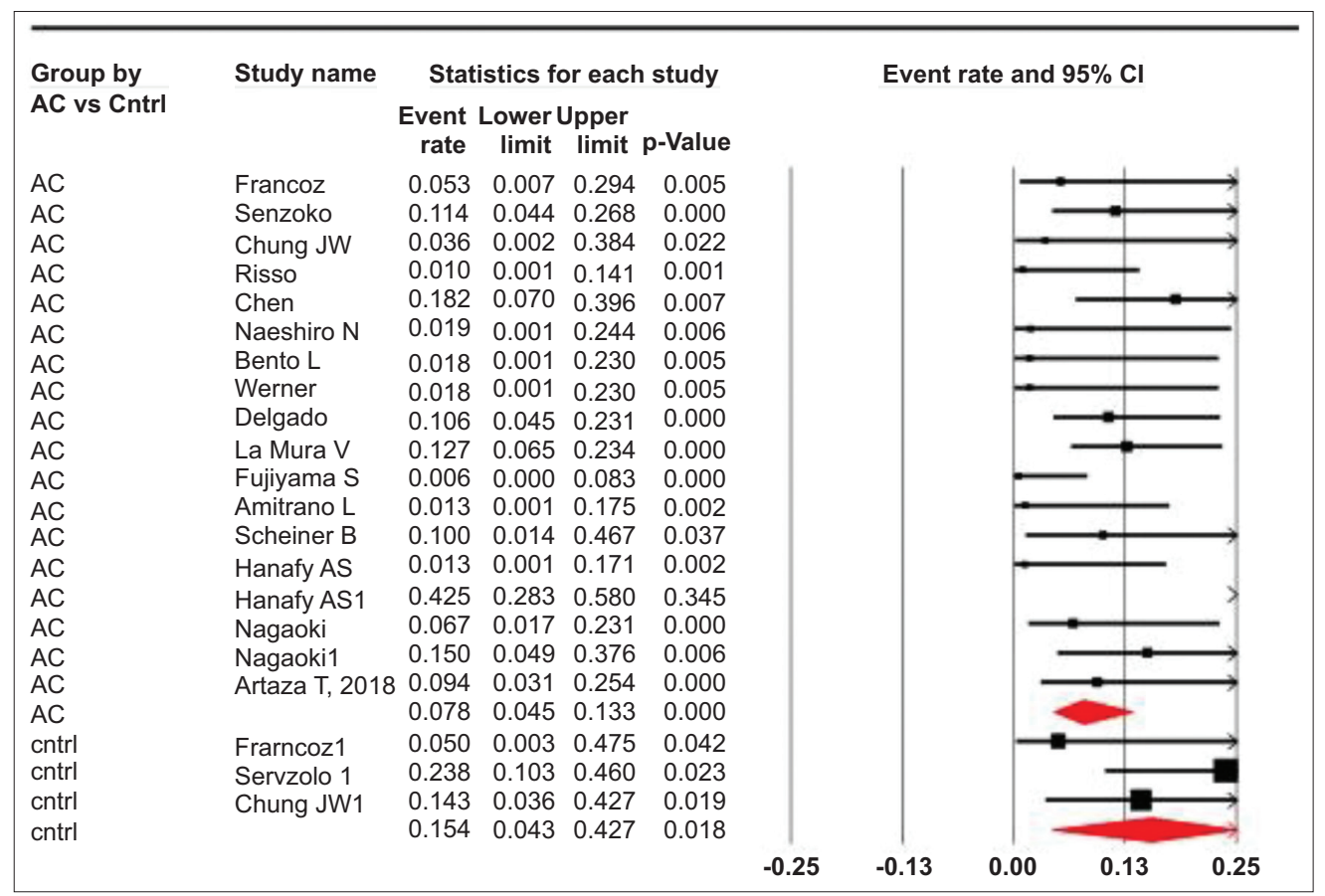

Supplementary Figure 3 Forest plot. Pooled rates, bleeding: anticoagulation (AC) vs. control (cntrl)

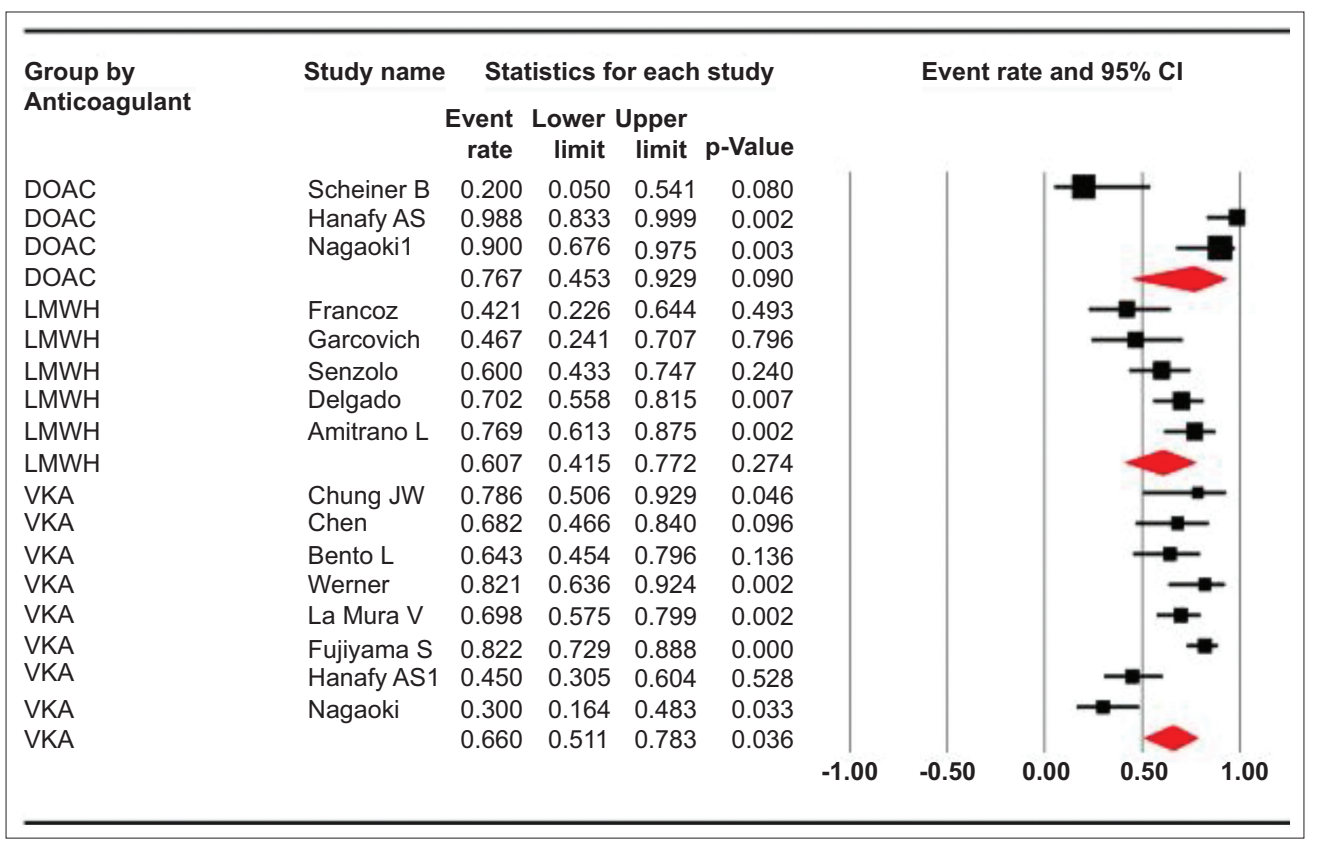

Supplementary Figure 4 Forest plot. Subgroup analysis, pooled rates, treatment responders: LMWH vs. VKA vs. DOAC $L M W H$, low molecular weight heparin; VKA, vitamin K antagonists; DOAC, direct oral anticoagulants 


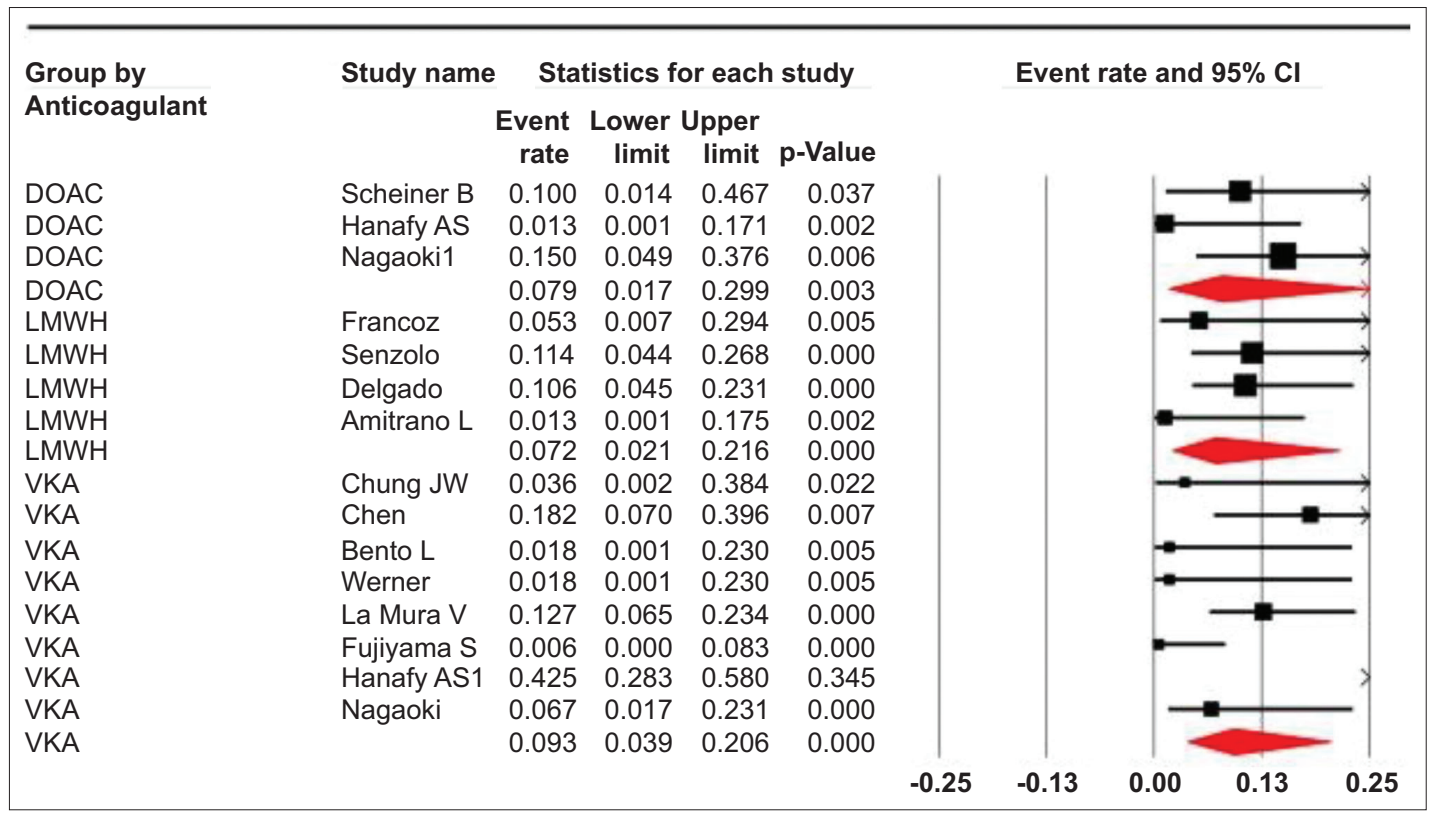

Supplementary Figure 5 Forest plot. Subgroup analysis, pooled rates, bleeding: LMWH vs. VKA vs. DOAC $L M W H$, low molecular weight heparin; VKA, vitamin K antagonists; DOAC, direct oral anticoagulants

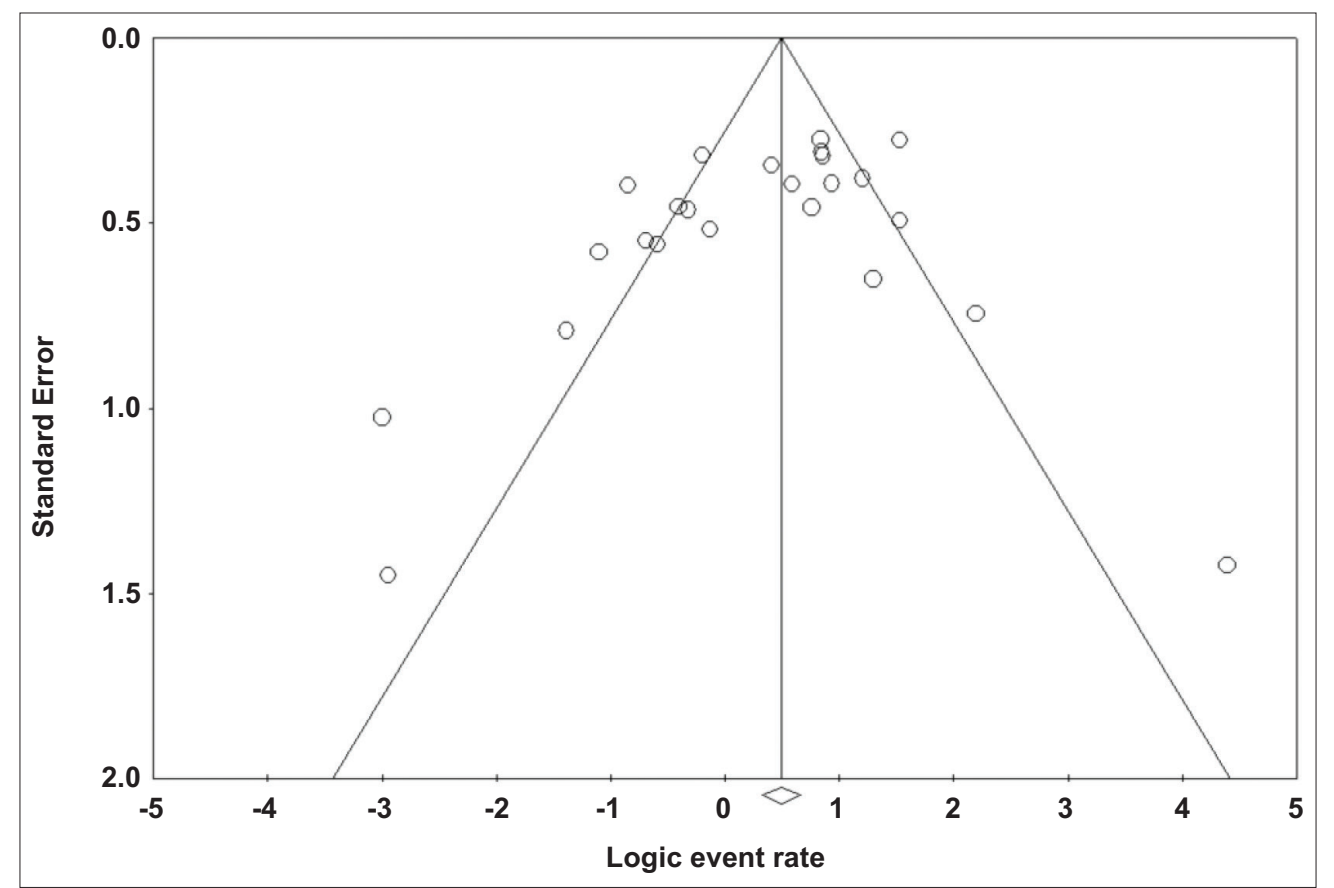

Supplementary Figure 6 Publication bias. Funnel plot 


\section{Appendix}

Appendix 1 Literature search strategy

Database(s): Embase 1988 to 2019, Ovid MEDLINE(R) 1946 to Present and Epub Ahead of Print, In-Process \& Other NonIndexed Citations and Ovid MEDLINE(R) Daily, EBM Reviews - Cochrane Central Register of Controlled Trials Dec 2019, EBM Reviews - Cochrane Database of Systematic Reviews 2005 to December 10, 2019

\begin{tabular}{|c|c|c|}
\hline \# & Searches & Results \\
\hline 1 & exp anticoagulants/ & 782992 \\
\hline 2 & anticoagulant therapy/ & 50181 \\
\hline 3 & exp 4-Hydroxycoumarins/ & 25566 \\
\hline 4 & $\begin{array}{l}\text { (anticoagula* or warfarin or heparin or coumadin or acenocoumarol or dicoumarol or phenprocoumon or "ethyl } \\
\text { biscoumacetate").ti,ab,hw,kw. }\end{array}$ & 559609 \\
\hline 5 & or/1-4 & 924639 \\
\hline 6 & exp portal vein/ or exp hepatic portal vein/ & 24430 \\
\hline 7 & exp thrombosis/ or thrombo. ti. & 593811 \\
\hline 8 & 6 and 7 & 4640 \\
\hline 9 & exp portal vein thrombosis/ & 10220 \\
\hline 10 & $\left(\right.$ port $^{\star}$ adj1 vein ${ }^{\star}$ adj1 thrombo ${ }^{*}$.ti,ab,hw,kw. & 15156 \\
\hline 11 & or $/ 8-10$ & 17805 \\
\hline 12 & exp liver cirrhosis/ & 218036 \\
\hline 13 & (cirrhotic or cirrhosis).ti,ab,hw,kw. & 295561 \\
\hline 14 & 12 or 13 & 295561 \\
\hline 15 & 5 and 11 and 14 & 1471 \\
\hline 16 & limit 15 to english language [Limit not valid in CDSR; records were retained] & 1358 \\
\hline 17 & 16 not $\left(\left(\right.\right.$ case $^{\star}$ adj3 $\left.\left.\left(\text { report }^{\star} \text { or series or stud }\right)^{\star}\right)\right) . t i, a b, h w, k w$. or case report/ or exp case study/) & 1041 \\
\hline 18 & 17 not ((exp animals/ or exp nonhuman/) not exp humans/) & 1032 \\
\hline 19 & remove duplicates from 18 & 794 \\
\hline
\end{tabular}

\section{SCOPUS}

1 TITLE-ABS-KEY ( ( anticoagula* OR warfarin OR heparin OR coumadin OR acenocoumarol OR dicoumarol OR phenprocoumon OR “ethyl biscoumacetate") )

2 TITLE-ABS-KEY ( $\left(\right.$ port $^{*} \mathrm{~W} / 1$ vein* W/1 thrombo* $\left.{ }^{*}\right)$

3 TITLE-ABS-KEY ( ( cirrhotic OR cirrhosis ) )

$4 \quad \# 1$ and \#2 and \#3

5 INDEX(embase) OR INDEX(medline) OR PMID $\left(0^{\star}\right.$ OR $1^{\star}$ OR $2^{*}$ OR $3^{*}$ OR $4^{*}$ OR $5^{*}$ OR $6^{*}$ OR $7^{*}$ OR $8^{*}$ OR $\left.9^{*}\right)$

$6 \quad$ \#4 and not \#5

7 DOCTYPE(ed) OR DOCTYPE(bk) OR DOCTYPE(er) OR DOCTYPE(no) OR DOCTYPE(sh) OR DOCTYPE(ch)

$8 \quad$ \#6 and not \#7

9 LANGUAGE(english)

$10 \quad \# 8$ and $\# 9$ 


\begin{tabular}{|c|c|c|c|}
\hline \multicolumn{4}{|c|}{ TITLE } \\
\hline Title & 1 & Identify the report as a systematic review, meta-analysis, or both. & 1 \\
\hline \multicolumn{4}{|c|}{ ABSTRACT } \\
\hline Structured summary & 2 & $\begin{array}{l}\text { Provide a structured summary including, as applicable: background; objectives; data } \\
\text { sources; study eligibility criteria, participants, and interventions; study appraisal and } \\
\text { synthesis methods; results; limitations; conclusions and implications of key findings; } \\
\text { systematic review registration number. }\end{array}$ & 3 \\
\hline \multicolumn{4}{|c|}{ INTRODUCTION } \\
\hline Rationale & 3 & Describe the rationale for the review in the context of what is already known. & 4 \\
\hline Objectives & 4 & $\begin{array}{l}\text { Provide an explicit statement of questions being addressed with reference to } \\
\text { participants, interventions, comparisons, outcomes, and study design (PICOS). }\end{array}$ & 4 \\
\hline \multicolumn{4}{|c|}{ METHODS } \\
\hline $\begin{array}{l}\text { Protocol and } \\
\text { registration }\end{array}$ & 5 & $\begin{array}{l}\text { Indicate if a review protocol exists, if and where it can be accessed (e.g., Web } \\
\text { address), and, if available, provide registration information including registration } \\
\text { number. }\end{array}$ & 5 \\
\hline Eligibility criteria & 6 & $\begin{array}{l}\text { Specify study characteristics (e.g., PICOS, length of follow up) and report } \\
\text { characteristics (e.g., years considered, language, publication status) used as criteria } \\
\text { for eligibility, giving rationale. }\end{array}$ & 5 \\
\hline Information sources & 7 & $\begin{array}{l}\text { Describe all information sources (e.g., databases with dates of coverage, contact with } \\
\text { study authors to identify additional studies) in the search and date last searched. }\end{array}$ & 5 \\
\hline Search & 8 & $\begin{array}{l}\text { Present full electronic search strategy for at least one database, including any limits } \\
\text { used, such that it could be repeated. }\end{array}$ & 5 \\
\hline Study selection & 9 & $\begin{array}{l}\text { State the process for selecting studies (i.e., screening, eligibility, included in } \\
\text { systematic review, and, if applicable, included in the meta-analysis). }\end{array}$ & 5 \\
\hline Data collection process & 10 & $\begin{array}{l}\text { Describe method of data extraction from reports (e.g., piloted forms, independently, } \\
\text { in duplicate) and any processes for obtaining and confirming data from investigators. }\end{array}$ & 6 \\
\hline Data items & 11 & $\begin{array}{l}\text { List and define all variables for which data were sought (e.g., PICOS, funding } \\
\text { sources) and any assumptions and simplifications made. }\end{array}$ & 6 \\
\hline $\begin{array}{l}\text { Risk of bias in } \\
\text { individual studies }\end{array}$ & 12 & $\begin{array}{l}\text { Describe methods used for assessing risk of bias of individual studies (including } \\
\text { specification of whether this was done at the study or outcome level), and how this } \\
\text { information is to be used in any data synthesis. }\end{array}$ & 8 \\
\hline Summary measures & 13 & State the principal summary measures (e.g., risk ratio, difference in means). & \\
\hline Synthesis of results & 14 & $\begin{array}{l}\text { Describe the methods of handling data and combining results of studies, if done, } \\
\text { including measures of consistency }\left(\text { e.g., } I^{2}\right) \text { for each meta-analysis. }\end{array}$ & 8 \\
\hline $\begin{array}{l}\text { Risk of bias across } \\
\text { studies }\end{array}$ & 15 & $\begin{array}{l}\text { Specify any assessment of risk of bias that may affect the cumulative evidence (e.g., } \\
\text { publication bias, selective reporting within studies). }\end{array}$ & 10 \\
\hline Additional analyses & 16 & $\begin{array}{l}\text { Describe methods of additional analyses (e.g., sensitivity or subgroup analyses, meta- } \\
\text { regression), if done, indicating which were pre-specified. }\end{array}$ & 9 \\
\hline \multicolumn{4}{|c|}{ RESULTS } \\
\hline Study selection & 17 & $\begin{array}{l}\text { Give numbers of studies screened, assessed for eligibility, and included in the review, } \\
\text { with reasons for exclusions at each stage, ideally with a flow diagram. }\end{array}$ & 8 \\
\hline Study characteristics & 18 & $\begin{array}{l}\text { For each study, present characteristics for which data were extracted (e.g., study size, } \\
\text { PICOS, follow up period) and provide the citations. }\end{array}$ & 8 \\
\hline $\begin{array}{l}\text { Risk of bias within } \\
\text { studies }\end{array}$ & 19 & $\begin{array}{l}\text { Present data on risk of bias of each study and, if available, any outcome level } \\
\text { assessment (see item 12). }\end{array}$ & 8 \\
\hline $\begin{array}{l}\text { Results of individual } \\
\text { studies }\end{array}$ & 20 & $\begin{array}{l}\text { For all outcomes considered (benefits or harms), present, for each study: (a) simple } \\
\text { summary data for each intervention group (b) effect estimates and confidence } \\
\text { intervals, ideally with a forest plot. }\end{array}$ & 9 \\
\hline
\end{tabular}


Appendix 2 (Continued)

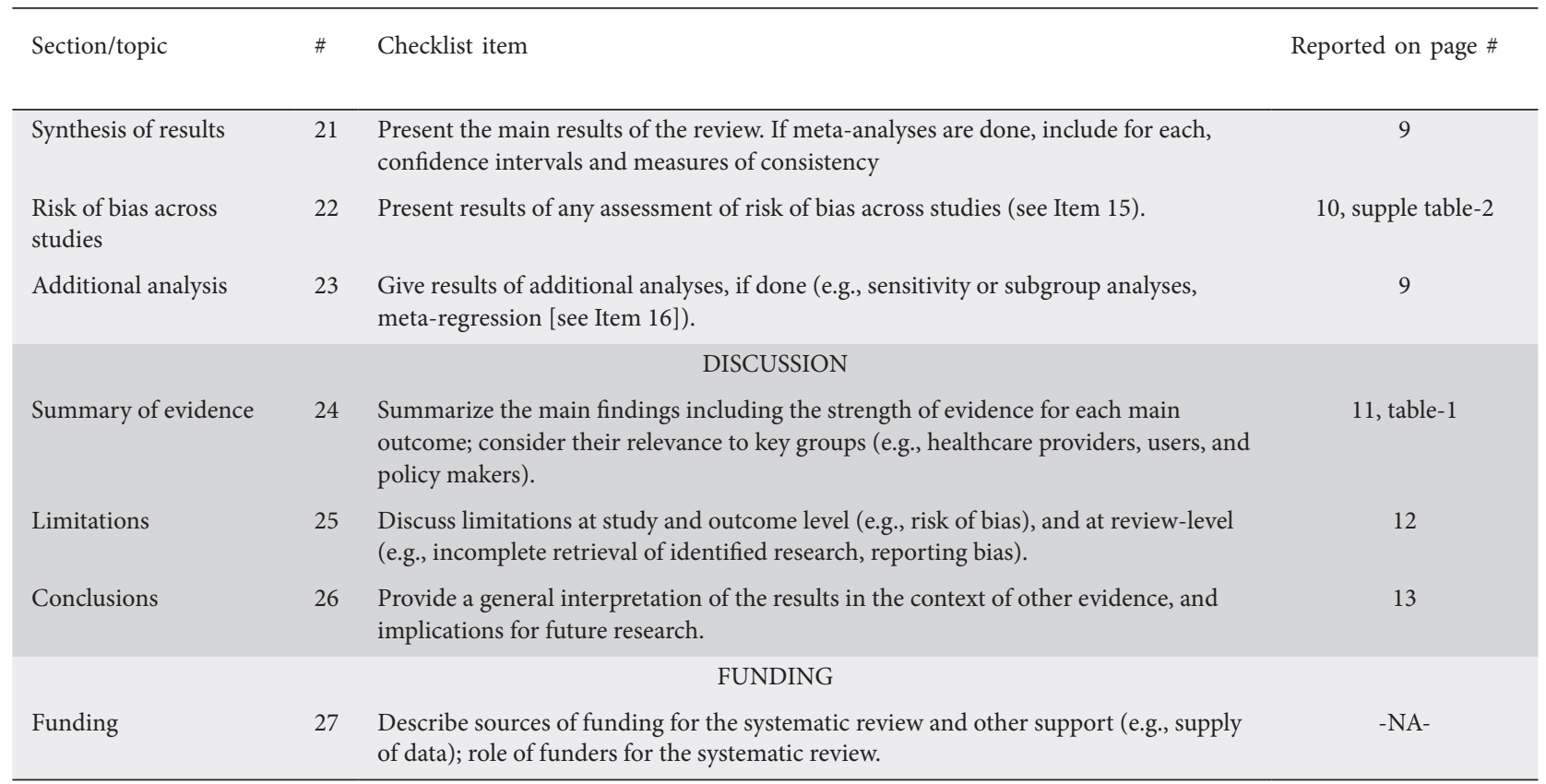

From: Moher D, Liberati A, Tetzlaff J, Altman DG, The PRISMA Group (2009). Preferred Reporting Items for Systematic Reviews and Meta-Analyses: The PRISMA Statement. PLoS Med 6(7): e1000097. doi:10.1371/journal.pmed1000097

\section{Appendix 3 MOOSE checklist}

Item No Recommendation

Reported on Page No

\begin{tabular}{|c|c|c|}
\hline \multicolumn{3}{|c|}{ Reporting of background should include } \\
\hline 1 & Problem definition & 4 \\
\hline 2 & Hypothesis statement & -NA- \\
\hline 3 & Description of study outcome(s) & 4 \\
\hline 4 & Type of exposure or intervention used & 4 \\
\hline 5 & Type of study designs used & 4 \\
\hline 6 & Study population & 4 \\
\hline \multicolumn{3}{|c|}{ Reporting of search strategy should include } \\
\hline 7 & Qualifications of searchers (e.g., librarians and investigators) & 5 , appendix 1 \\
\hline 8 & Search strategy, including time period included in the synthesis and key words & 5 , appendix 1 \\
\hline 9 & Effort to include all available studies, including contact with authors & 5 \\
\hline 11 & Search software used, name and version, including special features used (e.g., explosion) & Appendix 1 \\
\hline 12 & Use of hand searching (e.g., reference lists of obtained articles) & -na- \\
\hline 13 & List of citations located and those excluded, including justification & Appendix 1 \\
\hline 14 & Method of addressing articles published in languages other than English & -na- \\
\hline 15 & Method of handling abstracts and unpublished studies & 5 \\
\hline 16 & Description of any contact with authors & 6 \\
\hline \multicolumn{3}{|c|}{ Reporting of methods should include } \\
\hline 17 & $\begin{array}{l}\text { Description of relevance or appropriateness of studies assembled for assessing the hypothesis } \\
\text { to be tested }\end{array}$ & 5,6 \\
\hline 18 & Rationale for the selection and coding of data (e.g., sound clinical principles or convenience) & 5,6 \\
\hline
\end{tabular}




\begin{tabular}{|c|c|c|}
\hline Item No & Recommendation & Reported on Page No \\
\hline 19 & $\begin{array}{l}\text { Documentation of how data were classified and coded (e.g., multiple raters, blinding and } \\
\text { inter-rater reliability) }\end{array}$ & 5,6 \\
\hline 20 & $\begin{array}{l}\text { Assessment of confounding (e.g., comparability of cases and controls in studies where } \\
\text { appropriate) }\end{array}$ & 6 \\
\hline 21 & $\begin{array}{l}\text { Assessment of study quality, including blinding of quality assessors, stratification or } \\
\text { regression on possible predictors of study results }\end{array}$ & 6 \\
\hline 22 & Assessment of heterogeneity & 8 \\
\hline 23 & $\begin{array}{l}\text { Description of statistical methods (e.g., complete description of fixed or random effects } \\
\text { models, justification of whether the chosen models account for predictors of study results, } \\
\text { dose-response models, or cumulative meta-analysis) in sufficient detail to be replicated }\end{array}$ & 8 \\
\hline 24 & Provision of appropriate tables and graphics & Table 1, supplemental materials \\
\hline \multicolumn{3}{|c|}{ Reporting of results should include } \\
\hline 25 & Graphic summarizing individual study estimates and overall estimate & Supplementary materials \\
\hline 26 & Table giving descriptive information for each study included & Supplementary Table 1 \\
\hline 27 & Results of sensitivity testing (e.g., subgroup analysis) & 10 \\
\hline 28 & Indication of statistical uncertainty of findings & 10 \\
\hline \multicolumn{3}{|c|}{ Reporting of discussion should include } \\
\hline 29 & Quantitative assessment of bias (e.g., publication bias) & 10 \\
\hline 30 & Justification for exclusion (e.g., exclusion of non-English language citations) & -na- \\
\hline 31 & Assessment of quality of included studies & Supplementary Table 2 \\
\hline \multicolumn{3}{|c|}{ Reporting of conclusions should include } \\
\hline 32 & Consideration of alternative explanations for observed results & 11 \\
\hline 33 & $\begin{array}{l}\text { Generalization of the conclusions (i.e., appropriate for the data presented and within the } \\
\text { domain of the literature review) }\end{array}$ & $11,12,13$ \\
\hline 34 & Guidelines for future research & 13 \\
\hline
\end{tabular}

